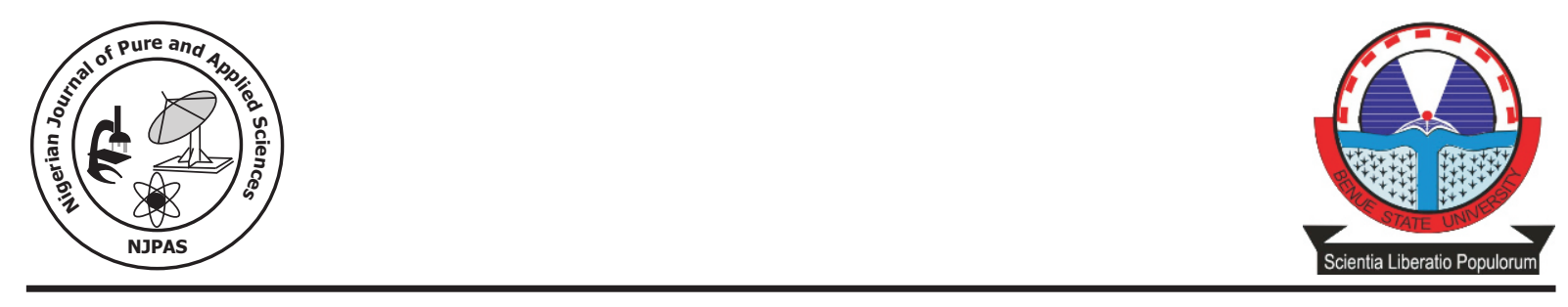

\title{
Estimation of Appropriate Stack Height at Industrial Layout, Makurdi, Benue State
}

\author{
${ }^{1}$ Ikyo B.A, ${ }^{1}$ Gbaorun F, ${ }^{1}$ Awua S.A., Sayid, S.A ${ }^{3}$ and ${ }^{2}$ Asaar G.B \\ ${ }^{1}$ Department of Physics, Benue State University, Makurdi, Nigeria \\ ${ }^{2}$ Department of Chemical sciences, University of Mkar, Mkar, Nigeria. \\ ${ }^{3}$ Hacness-Screens, Stevenage, Herts, UK SG1 3BB
}

\begin{abstract}
The prediction of appropriate stack height at the Makurdi industrial layout in Benue State of Nigeria is carried out using the point source Gaussian plume model. The model takes into account the ambient environmental conditions and emission source parameters to calculate and estimate the appropriate stack height for three prevailing atmospheric stability classes, A, D and F within the Makurdi Industrial layout. The research estimates an appropriate stack height of $\sim 65.0 \mathrm{~m}$ for the Makurdi industrial layout. The results set a baseline for environmental safety standards for industries operating at the industrial layout and can be adopted by the National Environmental Standard Enforcement and Regulatory Agency (NESERA), and other concerned authorities in environmental monitoring and pollution control.
\end{abstract}

\section{Introduction}

During industrial activities, air pollutants are produced and emitted to the immediate environment. These air pollutants are hazardous to humans, animals, vegetation and materials, consequently causing serious damage over time. The commonest industrial air pollutant is smoke produced from factory chimneys which consists predominantly of carbon particles and other combustible materials. Other industrial air pollutants include carbon (ii) oxide from automobile exhausts, hydrocarbons, organic acids and some oxides of sulphur and nitrogen which result from large power plants and low heat burners and furnaces. The effects produced by these pollutants include; tarnishing of building surfaces and clothing, corrosion of metal surfaces, collapse of leaf tissue (necrosis), bleaching or other colour changes (chlorosis) and alterations in growth of vegetation .It also causes fluorosis in livestock and affects weather as it reduces visibility, a situation that affects the operations of aeroplanes and automobiles and also reduces the amount of solar radiation reaching the earth, (Tsor, 2003). The most alarming of all is its health effects which include cancer of the skin and lungs, respiratory and cardiovascular illnesses such as bronchitis, asthma and tuberculosis, instant death etc.

The Gaussian plume model is based on the approximation that the concentration downwind of a point source in the atmospheric boundary layer is Gaussian, but with unequal dispersion coefficients in the horizontal and vertical directions. It describes the atmospheric dispersion of a puff in three dimensions, or a steady-state plume from a continuous source in two dimensions. Deriving the Gaussian dispersion equation 
requires the assumption of constant conditions for the entire plume travel distance from the emission source point to the downwind ground-level receptor. For a simple model, assuming that a plume traveling horizontally (in the $\mathrm{x}$-direction) at a mean speed (

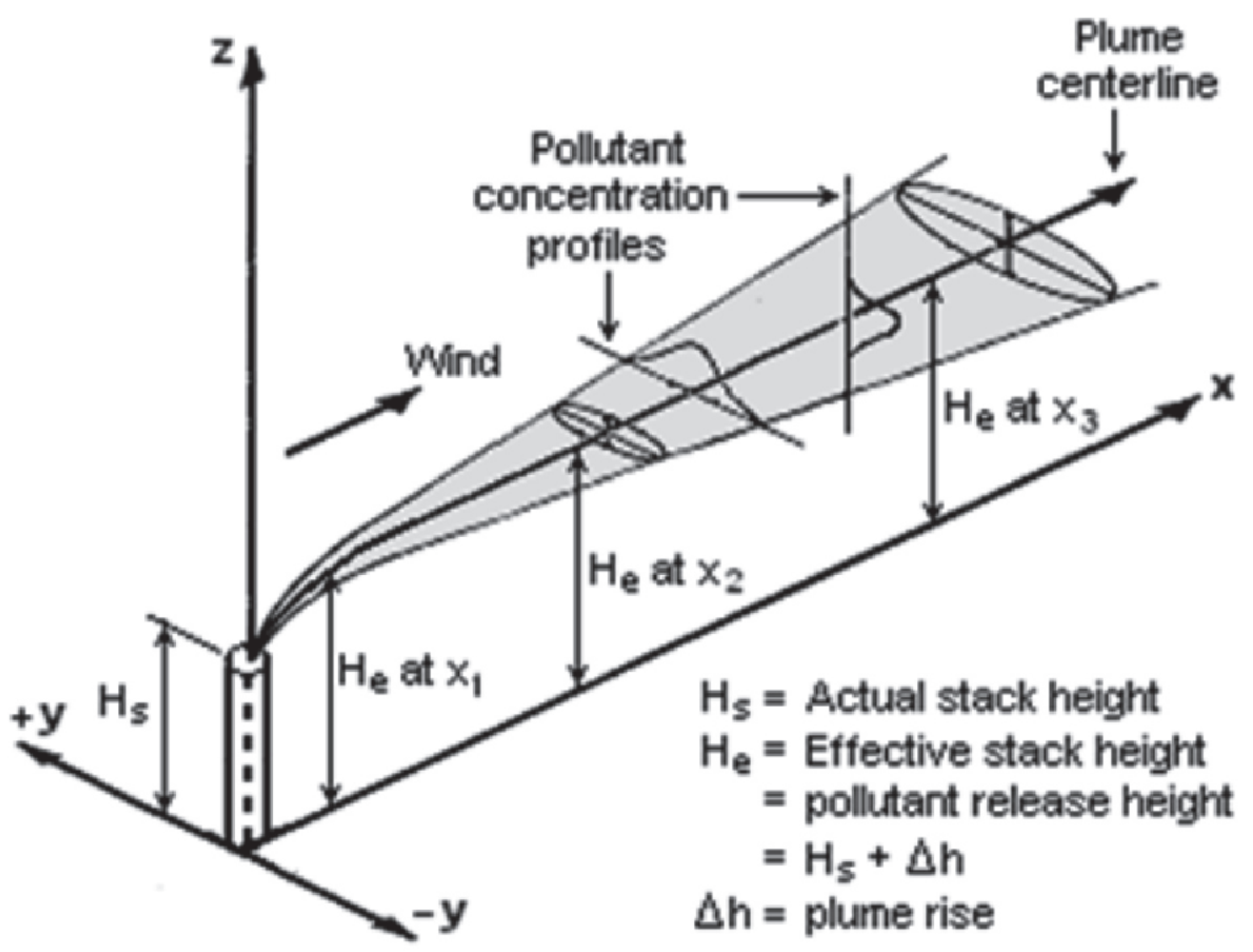

Figure 1: Illustration of plume centerline at height $\mathrm{H}_{e}$ as emitted from an elevated point source.

The concentration of pollutants downwind from such a point source is given by equation 1

$$
C_{(x, y, z)}=\frac{Q}{\pi u \delta_{y} \delta_{z}} \exp \left(\frac{-y^{2}}{2 \delta_{y}^{2}}\right) \exp \left(\frac{-H_{e}^{2}}{2 \delta_{z}^{2}}\right)
$$

where, $C_{(x, y, z)}$ Pollutant concentration $\left(\mathrm{kg} / \mathrm{m}^{3}\right)$ at the receptor located at $\left.(\mathrm{x}, \mathrm{y}, \mathrm{z})\right), Q$ is the source emission rate, $\delta_{y}$ and $\delta_{y}$ are dispersion coefficients in the $y$ and $z$ directions respectively and are functions of the downwind distances $\mathrm{x}$ from the source. $u$ $(\mathrm{m} / \mathrm{s})$ is the mean wind speed through the layer in which diffusion takes place while $H_{e}(\mathrm{~m})$ is the effective stack height.

The dispersion models are used to estimate or to predict the downwind concentration of air pollutants emitted from emission sources such as industrial plants and vehicular traffic (Briggs, 1976). The model is an important tool in the design of effective control strategies to reduce emissions of harmful air pollutants and serves governmental agencies in United States and similar ones in other nations such as NESREA in Nigeria tasked with regulations of the ambient air quality standards. In this work, we have employed the model to determine whether existing or proposed new industrial facilities at the Benue State Industrial Layout that produce gaseous effluent have stacks which are in compliance with the National Ambient Air Quality Standards (NAAQS). The result and analysis obtained from this work will be useful to the state ministry of environment, NESREA and investors intending to build new industries at the layout. The work will also serve as a reference 
material for other researchers and environmental safety officers.

\section{Materials and Methods}

This research was conducted at the industrial layout, Makurdi which is located $5 \mathrm{~km}$ on the out skirt of Makurdi town along Makurdi-Naka road in Benue State. It covers about 4 square kilometres of land. At the time of this research, the industries found at the industrial layout were: Lobi Cassava Flour Mills, Benkims Plastics Nig Ltd, Benfruits Nig Ltd, Benue Fertilizer and Chemical Company Ltd, Bashy Ventures Rice Mill Factory, Ahtell Industrial Products Ltd and Lobi Fresh Table Water. A few of these industries are owned by Private individuals and the others by the Government of Benue State. It is hoped that the industrial layout Makurdi, if fully developed, will house up to 100 small and large scale industries. At the time of this research, only five industries were operational; they include Lobi Cassava Flour Mills which was on full production was chosen for the pre-survey. Lobi Cassava Flour Mill has only one stack constructed on a relatively low flat terrain. The stack emission flow rate is continuous and constant and allows for a steady state analysis. The industry was operating for 24 hours a day.

As it is the case for most plume dispersion models, the work is in two phases, the input data acquisition phase and the simulation stage. The input phase was carried out by measuring and/or retrieving data on the industrial layout site. This data includes metrological conditions such as wind speed $(u)$ and direction, the stability classes which represent the amount of atmospheric turbulence, the ambient air temperature $\left(T_{A}\right)$ and the height to the bottom of any temperature inversion. The point source Gaussian plume model also requires the use of emission parameters such as, the stack height $\left(H_{s}\right)$, stack diameter $(D)$, effluent exit velocity $(V)$, effluent exit temperature $\left(T_{s}\right)$, source emission rate $(Q)$ obtained from the company's installation manual.

The parameters obtainable from the industry's installation manual through the technical department of the industry include; $\left.V=0.92 \mathrm{~m} / \mathrm{s}, T_{s}\right)=60^{\circ} \mathrm{C} H_{s}=20 \mathrm{~m}, D=0.5 \mathrm{~m}$, $\mathrm{Q}=9.17 \mathrm{~m}^{3} / \mathrm{s}$. The $T_{A}$ of $28{ }^{\circ} \mathrm{C}$ and $u$, of 0.27 $\mathrm{m} / \mathrm{s}$ were measured.

Stability class F among the three stability classes A, D and F (Very Unstable, Neutral and very Stable respectively) considered in this research reflect the most prevalent atmospheric condition of the layout.

The point source Gaussian plume model is being used in this research. The point source Gaussian plume model for determining the ground level concentration of equation 1 can be written as considering the image source:

$$
C_{(x, y, z)}=\frac{Q}{2 \pi \delta_{y} \delta_{z} u} \exp \left(-\frac{1}{2}\left(\frac{v}{\delta y}\right)\right)\left\{\exp \left(\frac{Z-H_{e}}{\delta z}\right)+\exp \left(-\frac{1}{2}\left(\frac{Z}{\delta z}+H_{e}\right)\right)\right\}
$$

$Z$ is the vertical coordinate relative to the ground.

Now for ground level concentration, , we have

$$
C_{(x, o, o)}=\frac{Q}{2 \pi \delta_{y} \delta_{z} u}\left\{\exp \left(\frac{-H_{e}{ }^{2}}{8 \delta z^{2}}\right)\right\}
$$

This implies that,

$$
C_{(x, o, o)}\left(\pi \delta_{y} \delta_{z} u\right)=Q\left\{\operatorname{xp}\left(\frac{-H_{e}{ }^{2}}{2 \delta z^{2}}\right)\right\}
$$

or

$\frac{C_{x}\left(\pi \delta_{y} \delta_{z} u\right)}{Q}=\exp \left(\frac{-H_{e}{ }^{2}}{2 \delta z^{2}}\right)$

$H_{e}$ can be deduced from equation (5) to be

$H_{e}{ }^{2}=\ln \left[\frac{C_{x}\left(\pi \delta_{y} \delta_{z} u\right)}{Q}\right]^{-1} \times 2 \delta_{z}{ }^{2}$

But $H_{e}$ and $H_{s}$ are related by the equation 7, where $\Delta H$ is the plume rise and $H_{s}$ is the actual stack height.

$H_{e}=\Delta H+H_{s}$

$\Delta H$ for stable atmosphere is calculated from equation 7 (Briggs 1972), we have

$\Delta H=2.6\left(\frac{F}{u S}\right)^{1 / 3}$,

where $F$ ans $S$ are the initial buoyancy flux of the emitted plume and stability factor respectively and are defined by the equations (9) and (10) respectively (Hoult et. al., 1969, 
Dop, 1992):

$\mathrm{F}=\mathrm{g}\left(\frac{T_{S}-T_{A}}{T_{S}}\right) \mathrm{v}\left(\frac{D}{2}\right)^{2}$
$S=\frac{g}{T_{A}}\left(\frac{\Delta T_{A}+0.01^{\circ} \mathrm{C} / \mathrm{m}}{\delta_{z}}\right)$

For unstable atmosphere where plume theoretically would never stop rising as a result of ambient air entrainment, and the plume rise equation changes to equation 11 (Dop, 1992)

$\Delta H=\frac{1.6 F^{1 / 3} x^{2 / 3}}{u}$

Equation 7 is used to compute values of $H_{s}$ i.e.

$H_{s}=H_{e}-\Delta H$

$\Delta H$ was calculated for stability classes A,D and $\mathrm{F}$ as presented in table 2 .

Table Calculated $\Delta H$ for stability class A, D and $\mathrm{F}$

\begin{tabular}{clll}
\hline Stability class & A & D & F \\
\hline$H^{(\mathrm{m})}$ & 0.42 & 1.53 & -1.55 \\
\hline
\end{tabular}

The dispersion coefficient $\delta_{y}$ and $\delta z$ (horizontal dispersion coefficient and vertical dispersion coefficient respectively) sometimes called standard deviations have units of meters and correspond to an air pollutant sampling time of 10 minutes. The dispersion coefficients are a function of the atmospheric stability class and the downwind distance $\mathrm{x}$ from the air pollutant emission source. The magnitude of $\delta_{y}$ and $\delta z$ dispersion coefficients can be estimated using the equations 12 and 13 (Slawson and Csanady, 1971).

$\delta y=a x^{b}$

$\delta y=c x^{d}+f$

Values for four of the stability dependent constants $(a, c, d$ and $f)$ are given in Table 1 below. It should be noted that there are different values for the downwind distance $\boldsymbol{x}=$ $\mathbf{1} \mathbf{k m}$ and $\mathrm{x}>1 \mathrm{~km}, b$ is always equal to 0.894 .

Table 2: Values for four of the stability dependent constants (a, c, d and f)

\begin{tabular}{llllllll}
\hline Stability class & \multicolumn{7}{c}{$\boldsymbol{x} \leq \mathbf{1} \mathbf{k m}$} \\
\hline & $a$ & $c$ & $d$ & $f$ & $c$ & $d$ & $f$ \\
\hline A & 213.00 & 440.80 & 1.041 & 9.27 & 459.70 & 2.094 & -9.60 \\
B & 156.00 & 106.60 & 1.149 & 3.30 & 108.20 & 1.098 & 2.00 \\
C & 104.00 & 61.00 & 0.911 & 0.00 & 61.00 & 0.911 & 0.00 \\
D & 68.00 & 33.20 & 0.725 & -1.70 & 44.50 & 0.516 & -13.00 \\
E & 50.50 & 22.80 & 0.675 & -1.30 & 55.40 & 0.305 & -34.00 \\
F & 34.00 & 14.35 & 0.740 & -0.35 & 62.60 & 0.180 & -48.60 \\
\hline
\end{tabular}

Source: (Pontiggia et al., 2009) 


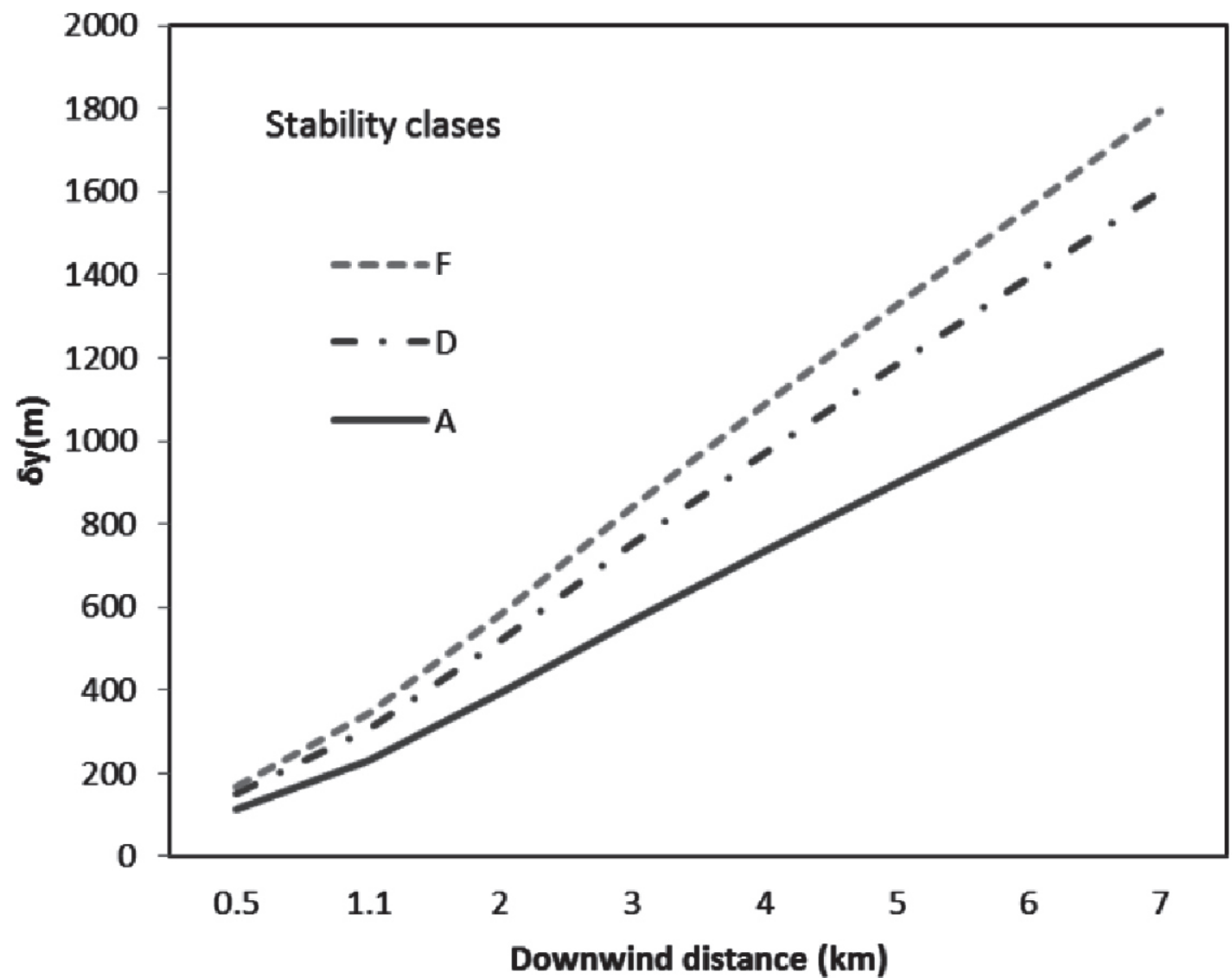

Figure 2: $\delta_{y}$ as a function of downwind distance $\mathrm{x}$ in km computed for stability classes A, D and $\mathrm{F}$

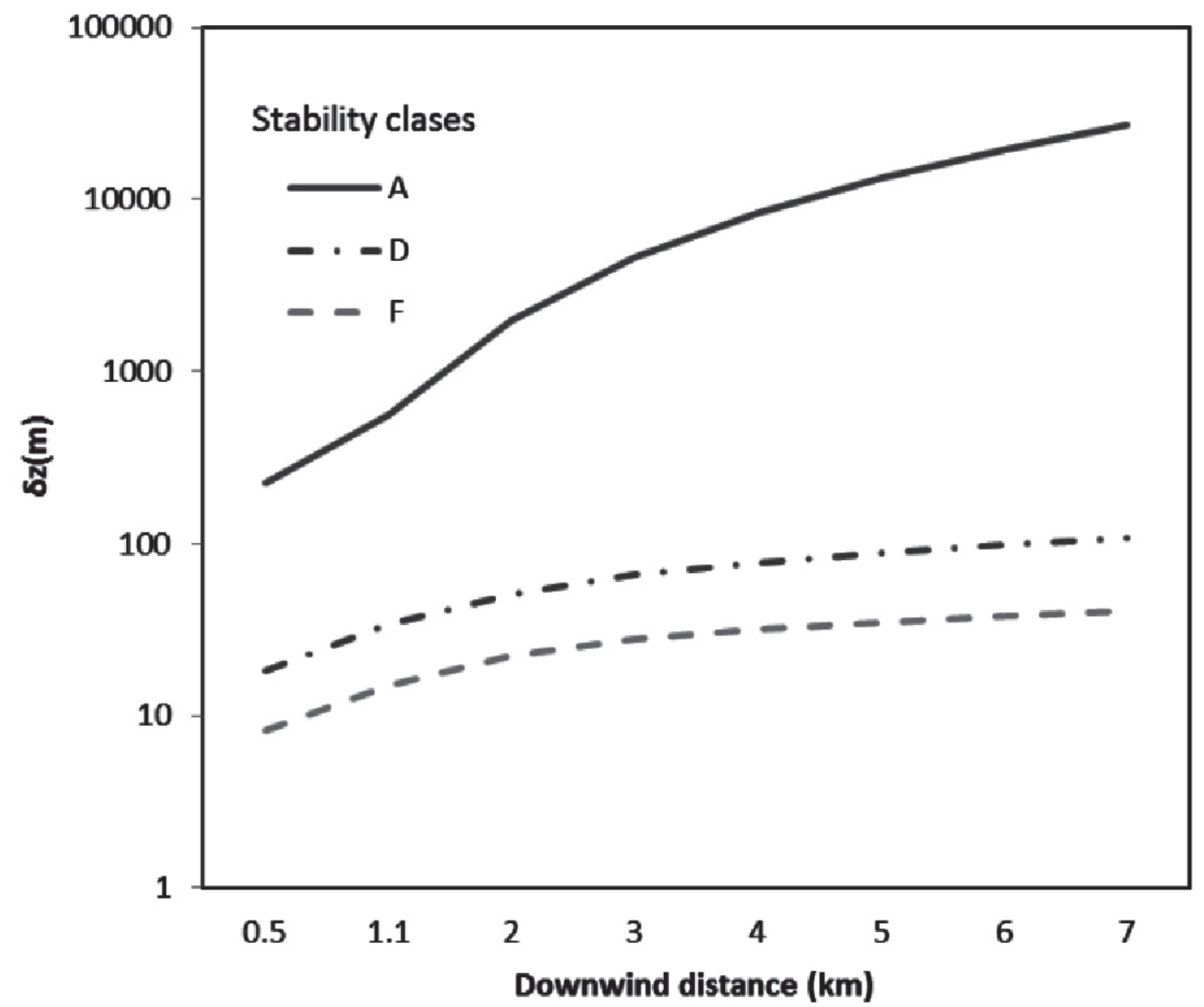

Figure 2: $\delta z$ as a function of downwind distance $\mathrm{x}$ in km computed for stability classes $\mathrm{A}, \mathrm{D}$ and $\mathrm{F}$ 


\section{Results and analysis}

After obtaining the preliminary data presented above the maximum ground level concentration of pollutant downwind along the plume centreline from the effluent source was calculated for stability classes A, D and F for downwind distances of $500 \mathrm{~m}$ and $2 \times 103 \mathrm{~m}$ respectively from the source point. $\mathrm{C}$ was calculated for various estimated effective stack height. The calculation is based on equation 6, however, the values were computed using the AJ Atmospheric Dispersion software (Raymond, 2002). The software is more of a calculator and computes both the $H_{e}$ and $C$. The computed values for maximum ground level concentration at $500 \mathrm{~m}$ and $2 \times 10^{3} \mathrm{~m}$ downwind, along the plume centreline are presented in figures 4 and 5 .

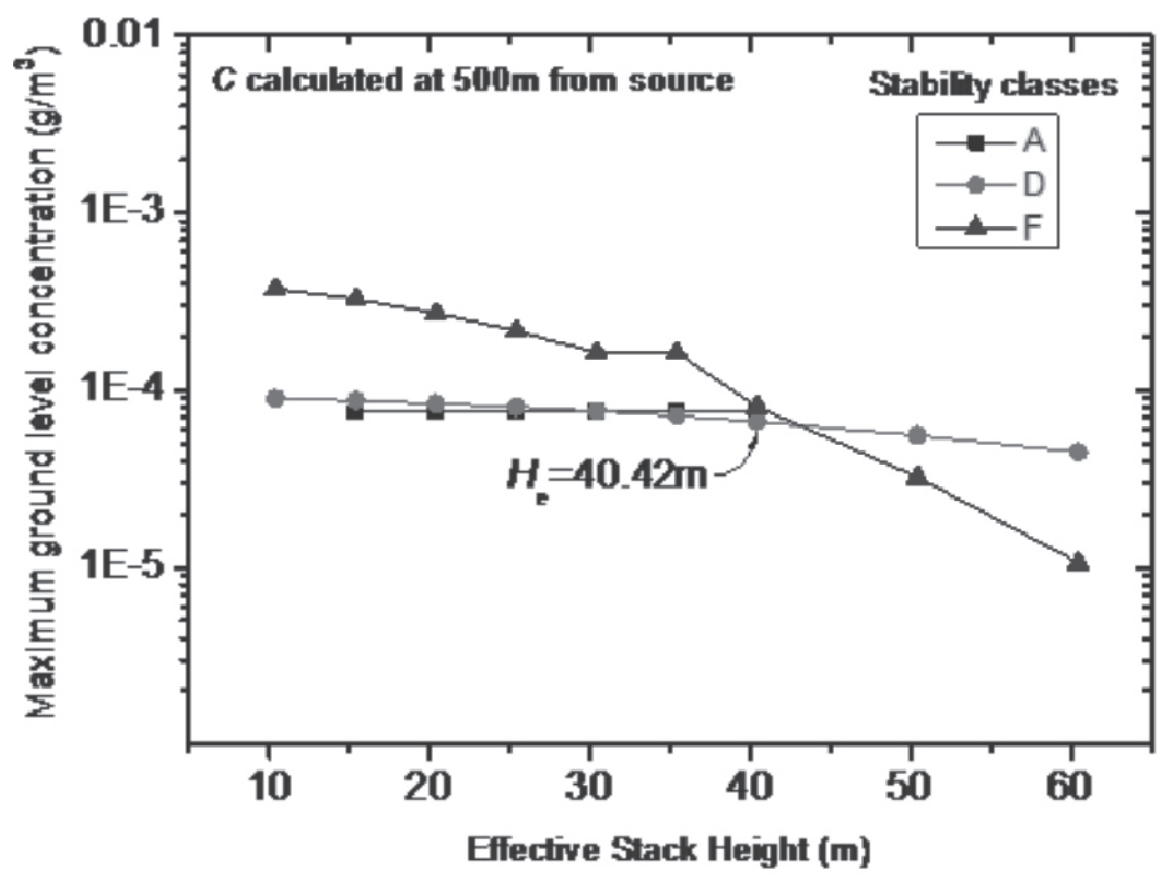

Figure 4: Computed maximum ground level concentration of pollutants at $500 \mathrm{~m}$ receptor point from source.

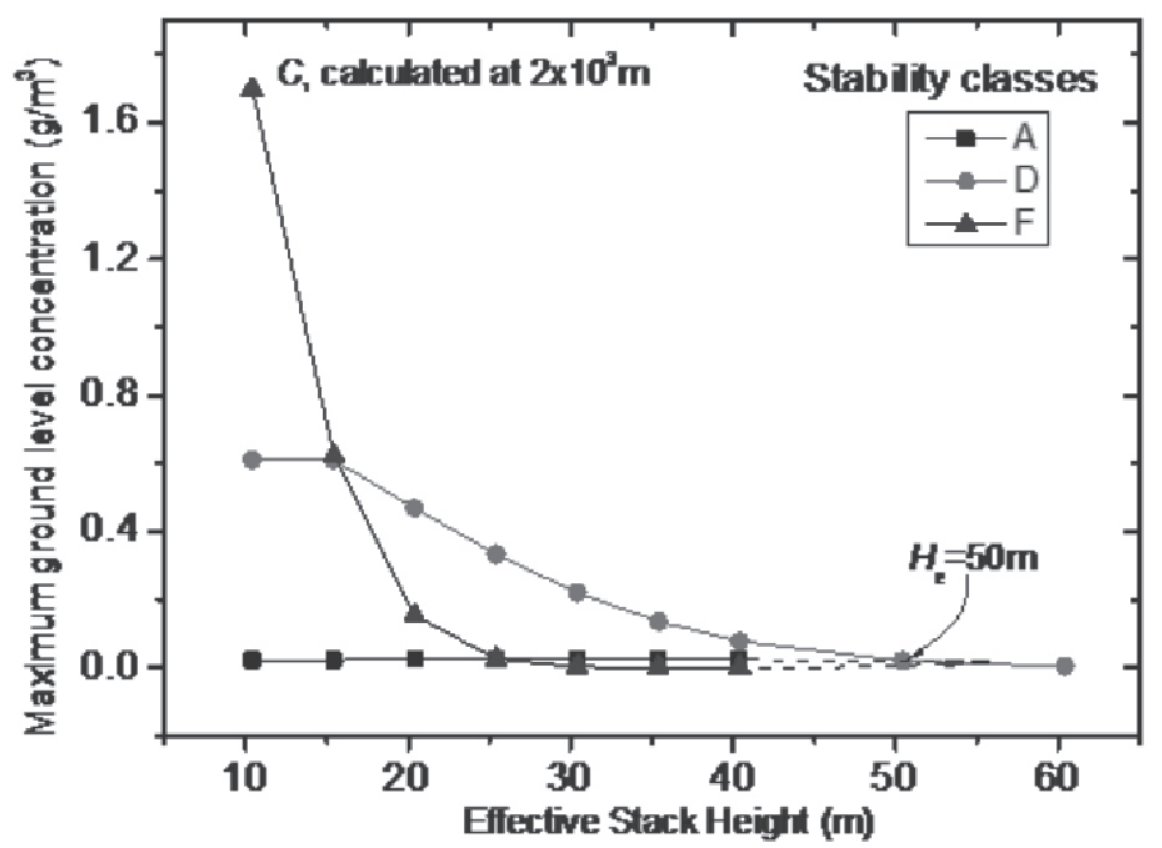

Figure 5: Computed maximum ground level concentration of pollutants at $2 \times 10^{3} \mathrm{~m}$ receptor point from source. 
In figure 4 , it is observed that the ground level concentration at $500 \mathrm{~m}$ from source decreases as the stack height increases for stability class $\mathrm{D}$ and $\mathrm{F}$ while remaining fairly constant for stability class A. since the atmospheric stability changes from time to time, it is always useful to estimate an appropriate stack height that will be suitable for other prevailing atmospheric conditions too. The average minimum ground level concentration for the three stability classes studied here is occurs at an effective stack height of $40.42 \mathrm{~m}$. At $2 \mathrm{~km}$ from source, $C$ decreases for all stability classes as $H_{e}$ increases. Even though the decrease for the three stability classes converges at $\sim 40 \mathrm{~m}$ (same as obtained for $500 \mathrm{~m}$ ), further extrapolation thus reveal that minimal effluents concentration are obtained as $H_{e}$ increases. It can be concluded that for minimal $C$, within the industrial layout and its environs the, the stack height should be at least $40 \mathrm{~m}$. Considering the average settlement distances of the two nearest communities, Tionsha and Agbough villages which are slightly beyond $1 \mathrm{~km}$, industries at the layout need to ensure that more specific investigation is carried out to ascertain an appropriate stack height for their site. In order to minimise the enormous problems of health and environment posed by the release of pollutants by industries at the industrial layout, it is recommended that the most appropriate stack height for industrial layout Makurdi is $40.0 \mathrm{~m}$.

\section{References}

Briggs, G. A. (1972). Chimney plumes in neutral and stable surroundings. Atmospheric Environment (1967), 6, 507-510.

Briggs, G. A. (1976). Plume rise predictions. 1975 Annual Report.

Dop, H. V. (1992). Buoyant plume rise in a Lagrangian framework. Atmospheric Environment. Part A. General Topics,
26, 1335-1346.

FEPA, (1998): National Guidelines and Standards for Industries, Effluents, Gaussian Emission and Hazardous Waste Management in Nigeria Decree 1998 (1988, No. 58)

Glendening, J. W., Businger, J. A. \& Farber, R. J. (1984). Improving plume rise prediction accuracy for stable atmospheres with complex vertical structure. Journal of the Air Pollution Control Association, 34, 1128-1133.

Hoult, D. P., Fay, J. A. \& Forney, L. J. (1969). A theory of plume rise compared with field observations. Journal of the Air Pollution Control Association, 19, 585590.

Ikyo B.A. (2007). Determination of Ground level concentration of pollutants from the Benue Cement Company (BCC) Plc Gboko, Nigeria (A Mathematical Approach). Journal of research in Physical Science, 3 (4):35-42.

Mayer, J. R. (2001). Connections in Environmental Sciences, A case study approach, $1^{\text {st }}$ Edition, McGraw-Hill companies Inc. New York.

Pontiggia, M., Derudi, M., Busini, V. and Rota, R. (2009). Hazardous gas dispersion: A CFD model accounting for atmospheric stability classes. Journal of hazardous materials, 171, 739-747.

Raymond, J. (2002). A J Design Software. In: SOFTWARE, A. J. A. D. D. (ed.). http://www.ajdesigner.com/phpdispersi on/plume_centerline_equation.php.

Schatzmann, M. (1979). An integral model of plume rise. Atmospheric Environment (1967), 13, 721-731.

Slawson, P. and Csanady, G. (1971). The effect 
of atmospheric conditions on plume rise. J. Fluid Mech, 47, 33-49.

Studies, N. R. C. B. O. E., Pollutants, T. C. O. A. I. A. H. E. T. A., Lioy, P. J., National Research Council. Commission on Geosciences, E. \& Resources (1991). Human exposure assessment for airborne pollutants: advances and opportunities, National Academy Press.
Tsor J.O (2003). The Characteristics of Atmospheric Aerosol during Harmattan in three Nigerian cities, M.Sc. thesis, Department of Physics, University of Jos, Nigeria.

Vesilind, P. A., Peirce, J. J. \& Weiner, R. F. (1990). Environmental Pollution and Control, Butterworth-Heinemann Limited. 